\title{
Effect modification, interaction and mediation: an overview of theoretical insights for clinical investigators [Corrigendum]
}

Corraini P, Olsen M, Pedersen L, Dekkers OM, Vandenbroucke JP, Clin Epidemiol. 2017;9:331-338.

For clarification, on page 334, Interaction section, left column, last paragraph, the interpretation of the relative risk due to interaction should read "This excess relative risk due to interaction indicates that the probability of serious upper gastrointestinal bleeding following combined use of aspirin and clopidogrel is much higher than the probability expected from the addition of the effects of the two drugs." where it previously read "By obtaining this relative risk due to interaction, the likelihood of serious upper gastrointestinal bleeding from the combined use of aspirin and clopidogrel was eight times higher than the likelihood expected by the addition of the two drugs."

\section{Publish your work in this journal}

Clinical Epidemiology is an international, peer-reviewed, open access, online journal focusing on disease and drug epidemiology, identification of risk factors and screening procedures to develop optimal preventative initiatives and programs. Specific topics include: diagnosis, prognosis, treatment, screening, prevention, risk factor modification,
Dovepress

systematic reviews, risk and safety of medical interventions, epidemiology and biostatistical methods, and evaluation of guidelines, translational medicine, health policies and economic evaluations. The manuscript management system is completely online and includes a very quick and fair peer-review system, which is all easy to use. 